\title{
Lithium disilicate posterior overlays: clinical and biomechanical features
}

\author{
Malchiodi Luciano $^{1} \cdot$ Zotti Francesca $^{1}$ (D) $\cdot$ Savoia Michela $^{2} \cdot$ Moro Tommaso $^{3} \cdot$ Albanese Massimo $^{1}$
}

Received: 12 June 2018 / Accepted: 6 June 2019/Published online: 14 June 2019

(C) The Author(s) 2019

\begin{abstract}
Objectives The aim of this study was to evaluate the survival rate of lithium disilicate overlays in increasing occlusal vertical dimension (OVD) in the setting of minimally invasive techniques and the restoration thicknesses at different tooth sites.

Materials and methods This is an observational study evaluating 43 lithium disilicate overlays (Lithium IPS e.max Press, Ivoclar Vivadent) on 8 patients, prepared with minimally invasive criteria over a follow-up period between 19 to 45 months (mean follow-up of 32 months). Occlusal vertical dimension's increase was planned using occlusal treatment plan and diagnostic waxup. Prior to adhesive cementation, restoration thicknesses were measured with a caliber. The survival rate was calculated by Kaplan-Meier analysis.

Results Restoration survival rates at 32 months were $97.7 \%$. One infiltration was observed, no cases of fracture occurred. The greatest thickness in monolithic restorations was detected in the cusp sides of teeth, whereas the thinnest was highlighted in the central fossa. The average amount of dental tissue removed during preparation was $0.98 \mathrm{~mm}$ in non-functional cusps, $0.88 \mathrm{~mm}$ in functional cusps, and $0.57 \mathrm{~mm}$ in the central fossa.

Conclusions Lithium disilicate posterior overlays show an excellent complication-free survival rate, and the material allows for conservative restorations with minimum thickness.

Clinical relevance Monolithic lithium disilicate overlays feature a satisfying 32-month survival rate. The technique allows to perform restorations with a minimal removal of dental tissue, while limiting fractures over time. Its esthetical performance is excellent.
\end{abstract}

Keywords Lithium disilicate $\cdot$ Posterior single tooth restorations $\cdot$ Thickness $\cdot$ Dental tissue

\section{Introduction}

The evolution of mechanical properties in restorative materials and adhesive cementation has led to the development of minimally invasive preparation criteria, which allow to preserve significant amounts of dental tissue with a consequent

Zotti Francesca

francesca.zotti@univr.it

Malchiodi Luciano

luciano.malchiodi@univr.it

Albanese Massimo

massimo.albanese@univr.it

1 Department of Surgical Sciences, Paediatrics and Gynecology, University of Verona, Policlinico "Giovanni Battista Rossi" Piazzale Ludovico Antonio Scuro, 10, 37134 Verona, Italy

2 Verona, Italy

3 Vicenza, Italy maximum reinforcement of dental elements. Importantly, the new materials have also contributed to overcoming the intrinsic problems related to the all-ceramic system, such as susceptibility to fracture and wear of antagonists. In recent years, the use of indirect adhesive restorations has also been extended to posterior teeth [1] achieving excellent results in terms of marginal closure, esthetic results, and reinforcement of the residual tooth structure, especially where cusps are covered $[1,2]$.

Among these new materials, lithium disilicate is one of the most promising, thanks to its high mechanical strength, extraordinary versatility, and excellent optical properties. Although glass ceramics are commonly indicated for esthetic restorations in the anterior area [3], the excellent biomechanical characteristics of lithium disilicate [4] make the material also suitable for monolithic inlays in the posterior teeth. In particular, by using lithium disilicate, posterior loading requirements can be met with a more conservative restoration, with a thickness of just $1.0 \mathrm{~mm}$, compared with the 1.5 to $2.0 \mathrm{~mm}$ commonly recommended for porcelain restoration [5]. Moreover, disilicate overlays allow to modify tooth 
occlusal surface and carry out wider rehabilitations in complex oral treatment plans. This feature makes corrections of occlusal relationship or increases in vertical dimension possible.

Hence in light of current evidence in the literature and our experience with this material, we aimed to evaluate the survival rate of lithium disilicate overlays performed to increase occlusal vertical dimension (OVD) by means of minimally invasive intervention and then evaluate the thickness of restorations in different teeth sites.

\section{Materials and methods}

The present study was an observational descriptive study evaluating 43 monolithic lithium disilicate overlay restorations (8 patients), to increase occlusal vertical dimension. The occlusal plane modifications had been planned during the treatmentplanning phase. Restorations were then performed using different techniques such as overlays, crowns, bridges, and veneers, in order to provide a comfortable occlusion for patients and provide complete oral rehabilitation; however, only the overlays were included in this study. An increase in vertical occlusion dimension had been required in all patients to fix temporomandibular joints and muscle relationships after dental wear or altered occlusal conditions. Inclusion criteria were overlay of posterior restoration, restoration of altered occlusal conditions and wear of teeth, teeth receiving endodontic treatment, and composite preceding restorations. Exclusion criteria were poor oral hygiene, active periodontitis, probing depths more than $4 \mathrm{~mm}$, and implant-supported restorations crowns [6].

Fig. 1 Minimal invasive preparations of teeth (clinical and cast models views)
Evaluation was limited to lithium disilicate overlays; the variables assessed were restoration thickness, average amount of dental tissue removed during preparation, and size of occlusal increase. Values collected were compared with those in the current literature. An observation period ranged between 19 and 45 months was considered (between December 2014 and January 2018) with an average time of follow-up of 32 months. Survival was defined as restoration being in situ with or without complications for the entire observation period. Assessment of survival was carried out for each restoration by the same trained examiner.

The 43 overlays were performed by using IPS e.max Press (Ivoclar Vivadent Manufacturing SRL, BZ, Italy) applied to 15 maxillary and 28 mandibular, following a precise cementation protocol.

At the first visit, an alginate dental impression was taken in each patient and cast models and diagnostic wax-up were made to plan the amount of occlusal rise needed for each dental element. By mounting on adjustable dental articulator dental casts, worn surfaces of teeth needing treatment were waxed and the amount of occlusal increase was planned aforetime on cast models.

Cavities were prepared complying with dental anatomy and maintaining the margins above the gum line in agreement with minimally invasive criteria in order to preserve tissues, avoid traumas, and reach a better prognosis for dental elements prepared (Fig. 1, Table 1) $[7,8]$.

Overlays were adhesively cemented using Variolink Esthetic (Ivolclar Vivadent Manufacturing SRL, BZ, Italy). The inner layer of restorations was etched by hydrofluoric acid 9.6\% (ENA etch, Micerium SPA, Avegno, Italy) for $30 \mathrm{~s}$ and then rinsed and dried. A silane coupling agent

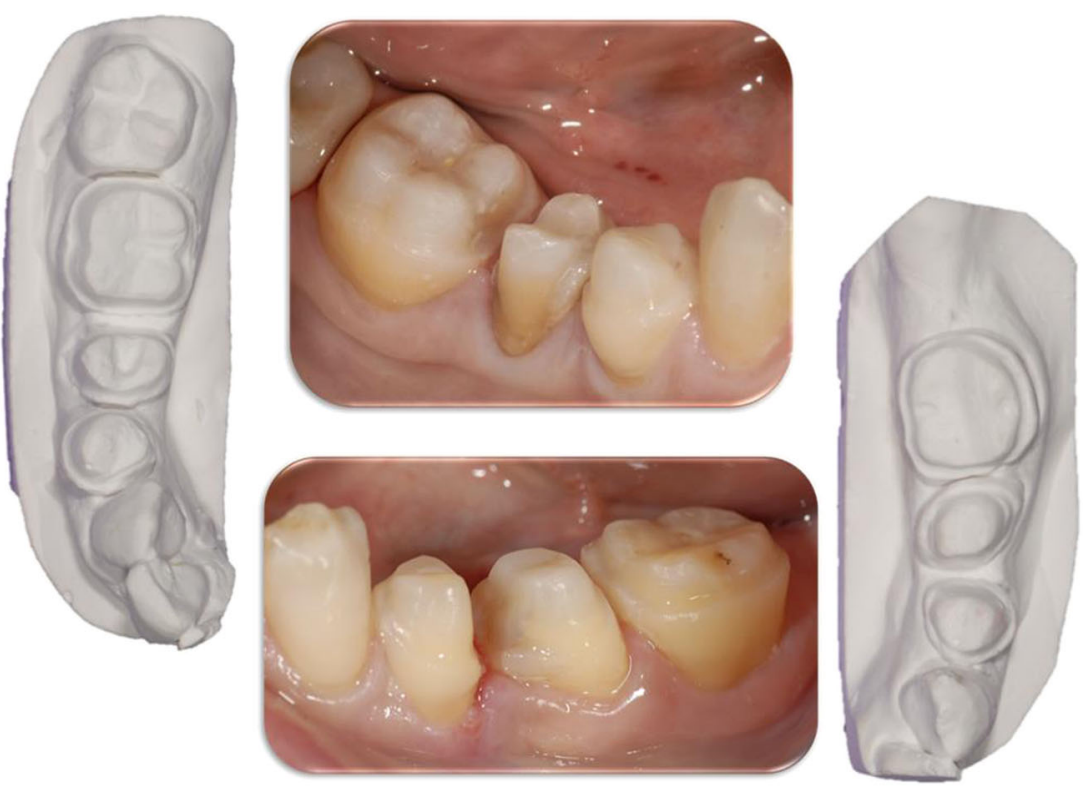


Table 1 Summary of criteria and conclusions about minimal invasive preparations

\begin{tabular}{|c|c|c|}
\hline Study & $\begin{array}{l}\text { Analyzed } \\
\text { thicknesses }\end{array}$ & Conclusions \\
\hline $\begin{array}{l}\text { Ma Li, Petra C. Guess, Yu Zhang (2013) } \\
\text { Load-bearing properties of minimal-invasive monolithic } \\
\text { lithium disilicate and zirconia occlusal onlays: finite el- } \\
\text { ement and theoretical analyses } \\
\text { Dental Materials }\end{array}$ & $\begin{array}{l}0.5 \mathrm{~mm} \\
1 \mathrm{~mm} \\
2 \mathrm{~mm}\end{array}$ & $\begin{array}{l}\text { The load-bearing capacity of lithium disilicate bonded to enamel } \\
\text { can approach } 75 \% \text { of that of zirconia with thicknesses be- } \\
\text { tween } 0.7 \text { and } 1.4 \mathrm{~mm} \text {. } \\
\text { The fracture load of ultra-thin inlays supported by enamel was } \\
\text { comparable with standard supported by dentin. }\end{array}$ \\
\hline $\begin{array}{l}\text { Petra C. Guess (2013) } \\
\text { Influence of preparation design and ceramic thicknesses on } \\
\text { fracture resistance and failure modes of premolar partial } \\
\text { coverage restorations } \\
\text { The Journal of Prosthetic Dentistry }\end{array}$ & $\begin{array}{l}0.5 \mathrm{~mm} \\
1 \mathrm{~mm} \\
2 \mathrm{~mm}\end{array}$ & $\begin{array}{l}\text { All premolar pressed lithium disilicate glass ceramic partial } \\
\text { coverage restorations revealed failure loads exceeding } \\
\text { physiologic mastication forces. } \\
\text { The reduction of thicknesses did not impair fracture resistance of } \\
\text { onlay restorations. }\end{array}$ \\
\hline $\begin{array}{l}\text { Fradeani et al. (2012) } \\
\text { Esthetic rehabilitation of a severely worn dentition with } \\
\quad \text { minimally invasive prosthetic procedures (MIPP) } \\
\text { The Journal of Prosthetic Dentistry }\end{array}$ & $0.8-1 \mathrm{~mm}$ & $\begin{array}{l}\text { The dental tissue preservation and the restoration bonding on } \\
\text { enamel guarantee sufficient resistance to restoration, even in } \\
\text { the presence of minimum thicknesses. }\end{array}$ \\
\hline $\begin{array}{l}\text { Morakot Piemjai et al. (2007) } \\
\text { Compressive Fracture Resistance of Porcelain Laminates } \\
\text { Bonded to Enamel or Dentin with Four Adhesive Systems } \\
\text { Journal of Prosthodontics }\end{array}$ & $\begin{array}{l}0.5 \mathrm{~mm} \\
1 \mathrm{~mm} \\
2 \mathrm{~mm}\end{array}$ & $\begin{array}{l}\text { The minimum enamel preparation for the } 0.5 \text {-mm porcelain } \\
\text { thickness achieved better fracture resistance for } \\
\text { enamel-bound porcelain compared with a deeper dentin } \\
\text { preparation to } 1.0-\mathrm{mm} \text { thickness. }\end{array}$ \\
\hline
\end{tabular}

(Monobond, Ivoclar Vivadent Manufacturing SRL, BZ, Italy) was applied for a minute onto the inner surfaces and then airdried. Subsequently, a layer of adhesive (Adhese Universal,
Ivoclar Vivadent Manufacturing SRL, BZ, Italy) was placed avoiding polymerization in order to not increase the thickness in the tooth/restoration surface.
Fig. 2 Lower arch, before and after repair

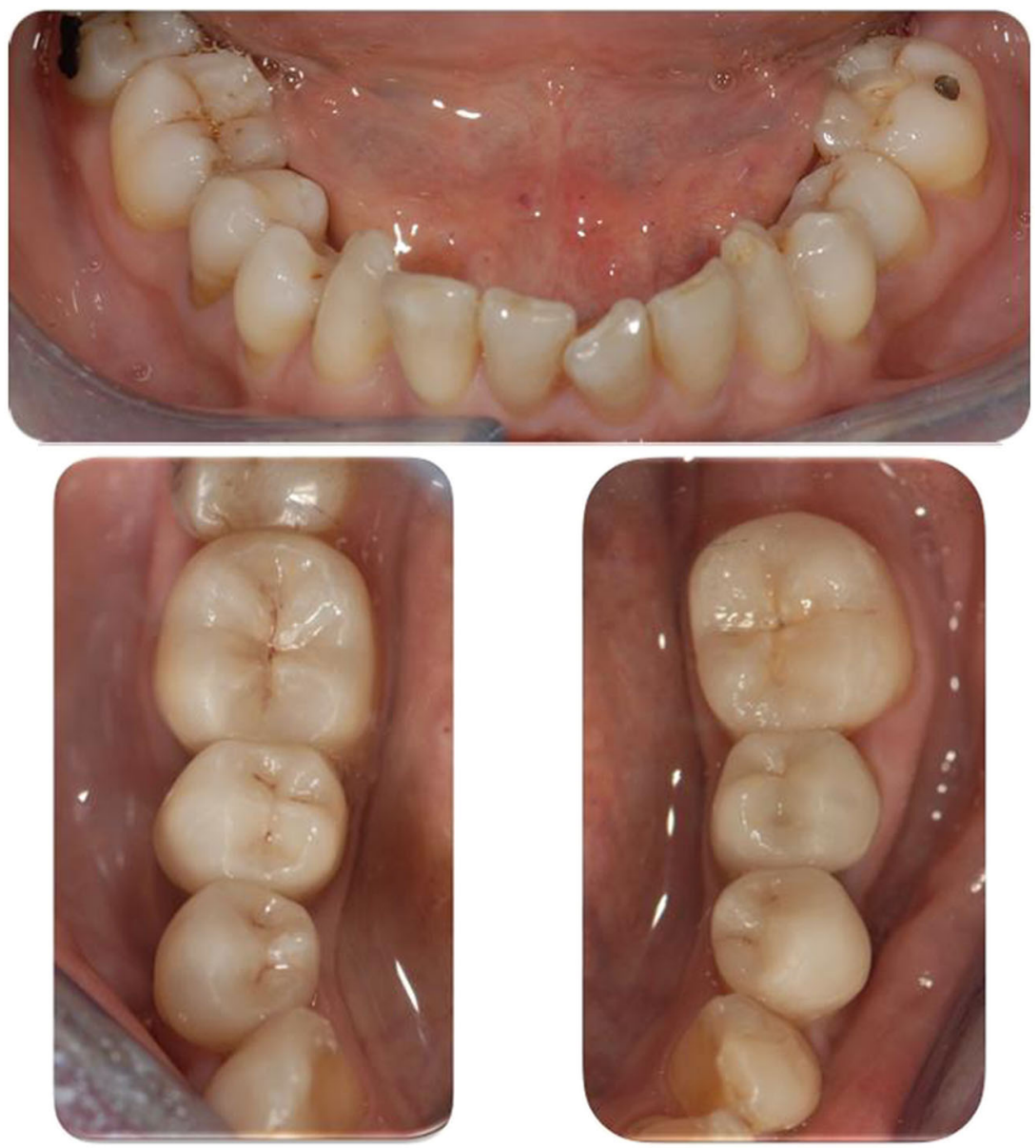


Graph 1 Kaplan-Meier diagram of survival rate on average follow-up

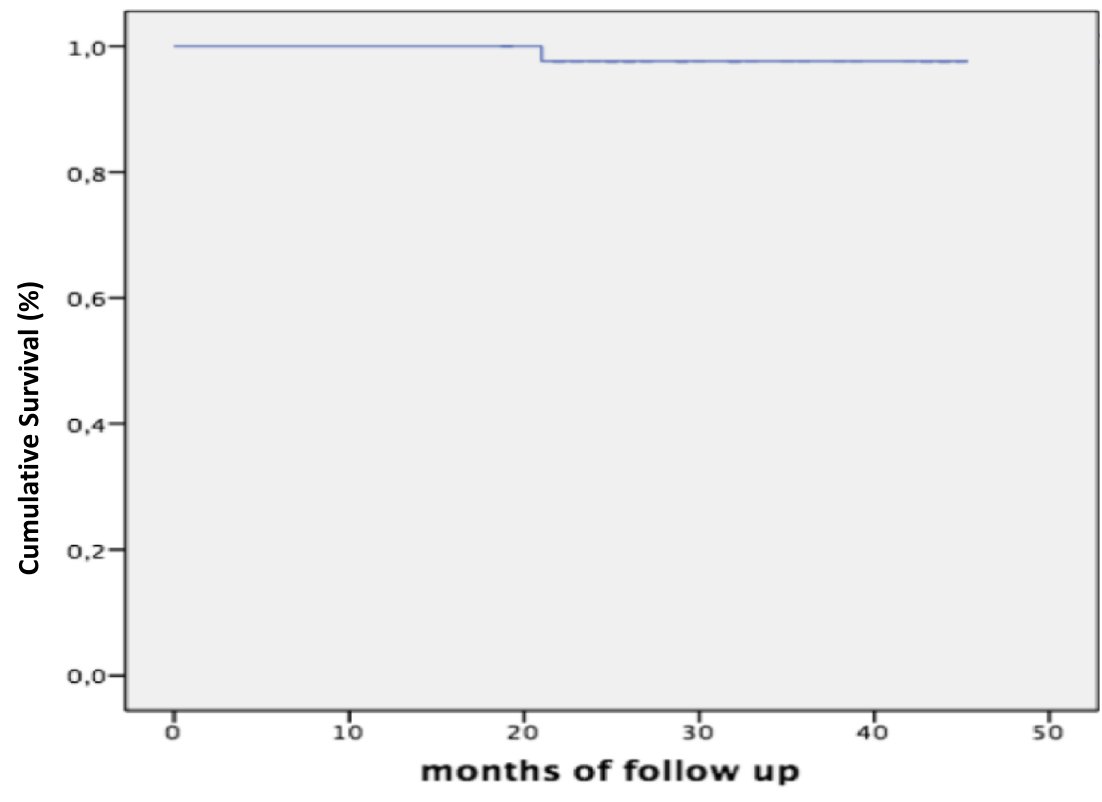

The operative field was isolated by use of a rubber dam; the dental cavity was then conditioned with $37 \%$ orthophosphoric acid (ENA total etch phosphoric acid 37\%, Micerium SPA, Avegno, Italy), $30 \mathrm{~s}$ for enamel, and $15 \mathrm{~s}$ for dentin, being careful to protect contiguous teeth. Dental surfaces were then abundantly rinsed and air-dried. Etch \& rinse bonding was placed (Adhese Universal VivaPen, Ivoclar Vivadent Manufacturing SRL, BZ, Italy) but not polymerized to avoid incongruous thicknesses on the tooth/restoration surface. Cementation was performed with Variolink Esthetic (Ivoclar Vivadent Manufacturing SRL, BZ, Italy) placed on the inner surface of the overlay. The overburden was removed with a brush before polymerization (1 min per surface), and margins were finished with a rubber pad. Occlusion was assessed and polishing was carried out.

\section{Evaluation}

Each complication was considered a statistical event; cumulate survival was recorded using Kaplan-Meier analysis.

The thickness of restoration is represented by the sum of extent of the occlusal increase and the amount of dental tissue removed during the preparation. Appraisal of restoration thickness included measurement with a thickness gauge and measurements of the functional cusp, non-functional cusp, and the central point of the fossa of prosthetic restorations. For each of these landmarks, the mean and standard deviation were calculated.

Measurement of molar overlay thicknesses of functional and non-functional cusps was performed for both the mesial portion and the distal portion; these were then expressed as a single value. The results obtained from the thickness analysis were compared with those present in the literature. A further evaluation on overlays thickness was carried out by subgroup characterization: very thin, thin, medium, and thick.

The amount of dental tissue removed was measured using a cutter of known size during preparation, and the thickness of overlays was measured using a millimetric thickness gauge. The extent of the occlusal rise was obtained by the difference between these two values. Subsequently, the ratios of extent of occlusal increase and of amount of dental tissue removed were determined within the overlay thickness, and a $t$ test was performed to compare the meanings of these two elements.

All values are expressed as mean \pm standard deviation. Statistical tests were considered significant for $P \leq 0.05$.
Table 2 Mean values of thickness $(\mathrm{mm}) \pm$ standard deviations at different landmarks, statistical significance, and clinical results

\begin{tabular}{llll}
\hline & $\begin{array}{l}\text { Thickness in non-functional } \\
\text { cusps }\end{array}$ & $\begin{array}{l}\text { Thickness in functional } \\
\text { cusps }\end{array}$ & $\begin{array}{l}\text { Thickness in the central } \\
\text { point of the fossa }\end{array}$ \\
\hline Mean $\pm \mathrm{SD}$ & $2.06 \pm 0.49$ & $1.94 \pm 0.39$ & $1.19 \pm 0.31$ \\
Reference value & $\geq 0.7 \mathrm{~mm}$ & $\geq 0.7 \mathrm{~mm}$ & $\geq 0.7 \mathrm{~mm}$ \\
Null hypothesis H0 & T-NFC $<0.7 \mathrm{~mm}$ & T-FC $<0.7 \mathrm{~mm}$ & T-CF $<0.7 \mathrm{~mm}$ \\
Significance of t-test & $<0.001$ & $<0.001$ & $<0.001$ \\
Result & $\geq 0.7 \mathrm{~mm}$ & $\geq 0.7 \mathrm{~mm}$ & $\geq 0.7 \mathrm{~mm}$ \\
\hline
\end{tabular}

$T$ thickness, $N F C$ non-functional cusps, $F C$ functional cusps, $C F$ central point of the fossa 


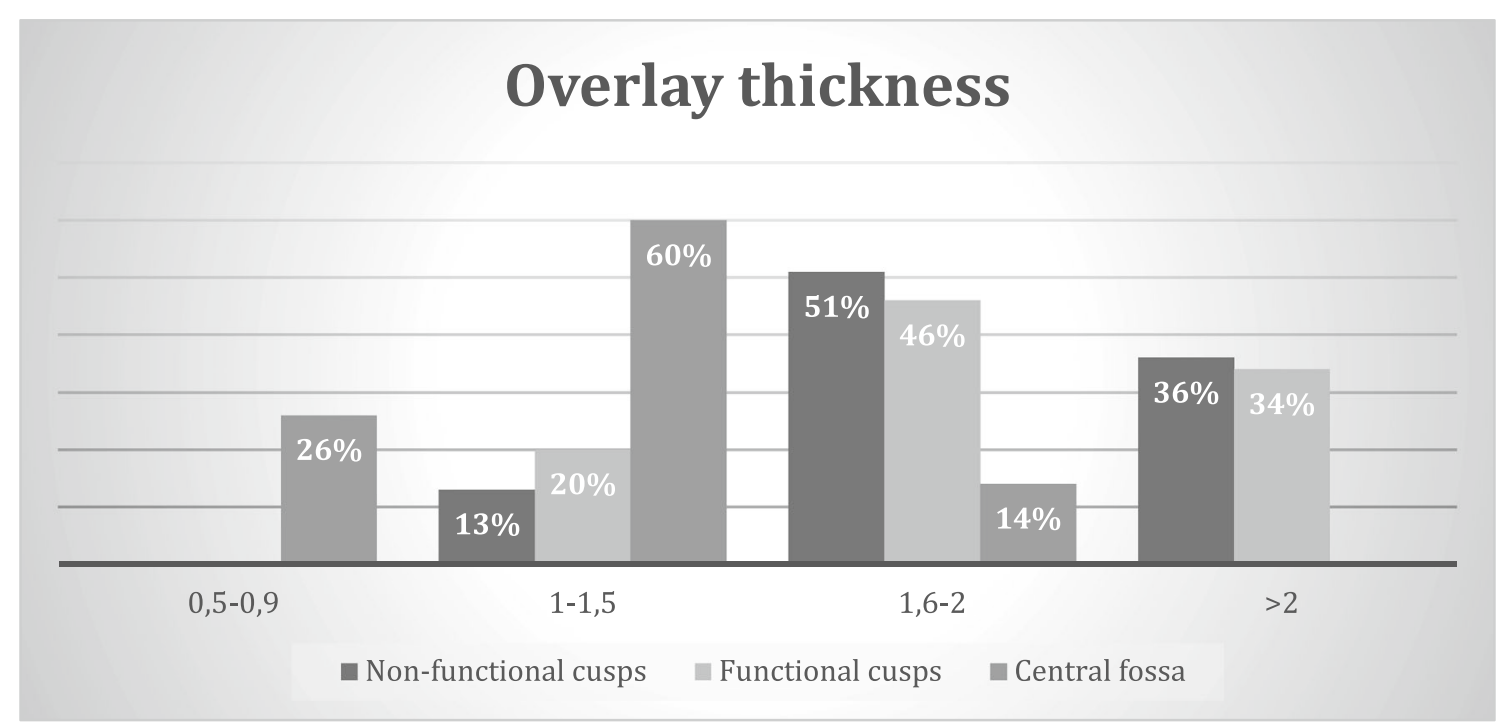

Graph 2 Representation of thickness (mm) at different landmarks of restoration

All statistical analyses were performed using Statistical Package for Social Sciences Version 22.0 (SPSS Inc., Chicago, IL).

\section{Results}

In this study, 43 overlays were performed in 8 patients. The study enrolled patients aged 47 to 67 years (average $57.9 \pm 7.22$ y.o.). The follow-up was 32 months (range 19-45 months). Eighteen molars (42\%) and 25 premolars $(58 \%)$ had been restored, in detail, 15 (35\%) overlays in the maxillary arch and $28(65 \%)$ in the mandibular (Fig. 2).
A case of infiltration occurred, but no cases of dental fracture or overlay fracture were noticed. The success rate was 97.7\% as calculated on average follow-up (Graph 1).

The single infiltration observed received endodontic treatment; the margin was reshaped and a composite restoration was carried out.

Values obtained by thickness analysis are shown in Table 2.

The value, expressed as mean \pm standard deviation, is compared with the reference values reported in the literature ( $t$ test).

Graph 2 shows the percentage of different thickness of restorations, very thin $(0.5-0.9 \mathrm{~mm})$, thin $(1-1.5 \mathrm{~mm})$, medium $(1.6-2 \mathrm{~mm})$, thick $(>2 \mathrm{~mm})$, at the restorations landmarks.

\section{OVERLAY THICKNESS COMPONENTS}

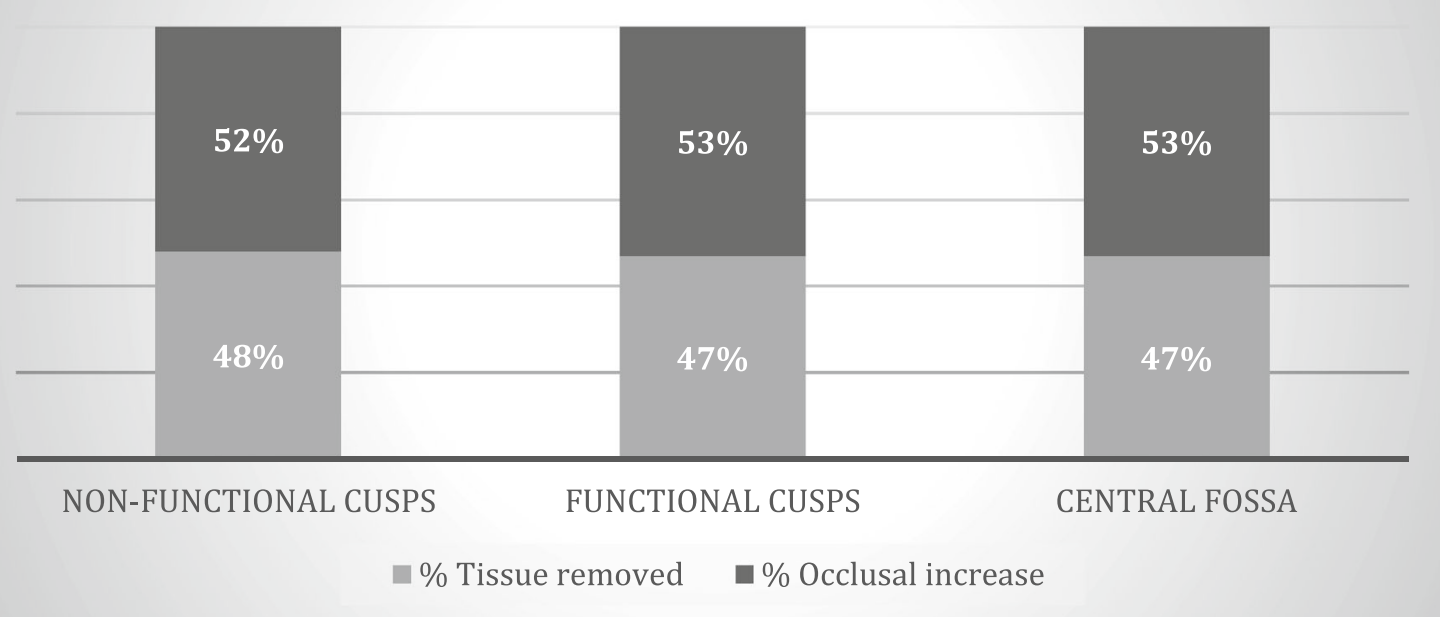

Graph 3 Average ratio (percentage) of tissue removed and occlusal increase within the thickness of overlays 
Table 3 Ratio of occlusal increase and removed tissue, $P$ values

$\begin{array}{lll}\text { Percentage of occlusal increase } & \text { NFC } & 52 \% \\ & \text { FC } & 53 \% \\ \text { Percentage of tissue removed } & \text { CF } & 53 \% \\ & \text { NFC } & 48 \% \\ & \text { FC } & 47 \% \\ \text { CF } & 47 \%\end{array}$

$P$ value in $\mathrm{NFC}=0.366$

$P$ value in $\mathrm{FC}=0.112$

$P$ value in $\mathrm{CF}=0.128$

$F C$ functional cusps, $N F C$ non-functional cusps, $C F$ central point of the fossa

On functional and non-functional cusps, the thickness was remarkably higher than $1.5 \mathrm{~mm}$ ( $87 \%$ and $80 \%$, respectively). Instead, in the central point of the fossa, the thickness was found to be thinner ( $86 \%$ is less than $1.5 \mathrm{~mm}$ ).

The ratios of the amount of dental tissue removed and occlusal increase were defined in relation to the thickness at each landmark, and percentage of each value was calculated (Graph 3).

Table 3 describes the extent of these components in detail.

Results of the $t$ test performed to assess ratios of removed tissue and occlusal increase did not evidence any statistically significant difference in percentage values of tissue removed and of occlusal increase in any landmark ( $t$ test $\leq 0.05)$, which indicates that, within the thickness of overlay, the amount of tissue removed is likely to be the same as occlusal increase entity (Table 3).

Graph 4 shows that the depths of most of preparation are less than $1 \mathrm{~mm}$, according to minimum invasive criteria. The amount of tissue removed was less than or equal to $1 \mathrm{~mm}$ in $59 \%$ of preparations of the non-functional cusps, $74 \%$ of the functional cusps, and $93 \%$ of the central fossa.

\section{Discussion}

The aim of the present study was to evaluate specific characteristics of restorations, specifically in the setting of increasing vertical dimension in patients with worn dentition. Particular attention was set on the possibility of performing minimally invasive preparations and evaluating the thicknesses of the material used in terms of restoration survival.

Our choice towards lithium disilicate was driven by its slightly higher hardness and resistance compared with those of tooth enamel, which makes it suitable for an increase in vertical dimension. This allows to maintain the material's wear and tear similar to that occurring with the original enamel, thus limiting, at least in part, the gnathologic consequences in many cases typical of extended occlusions with protheses.

Overall results are encouraging. As expected, restoration survival rates in our study were in agreement with current data from the literature on posterior restorations [7, 9], with $97.7 \%$ at 32 months and no restoration fractures observed [7, 9, 10]. Moreover we were able to perform a minimally invasive preparation, while maintaining adequate thicknesses and avoiding pointless loss of dental tissue, as suggested by current evidence.

Studies in the literature have estimated the depth of preparation for traditional monolithic ceramic systems needed to provide resistance to tensile stress of inner cementation surfaces under occlusal load to be approximately 1.5-2 $\mathrm{mm}[1,3$, 11]. With specific reference to for IPS e.max Press lithium disilicate ceramic, most manufacturers recommend a minimum thickness of $1.5 \mathrm{~mm}$; however, such indications are mostly based on in vitro tests and do not ensure enforceable clinical results [12]. In recent years several studies have evaluated the resistance of minimum thicknesses of monolithic lithium disilicate IPS e.max Press restorations and have found

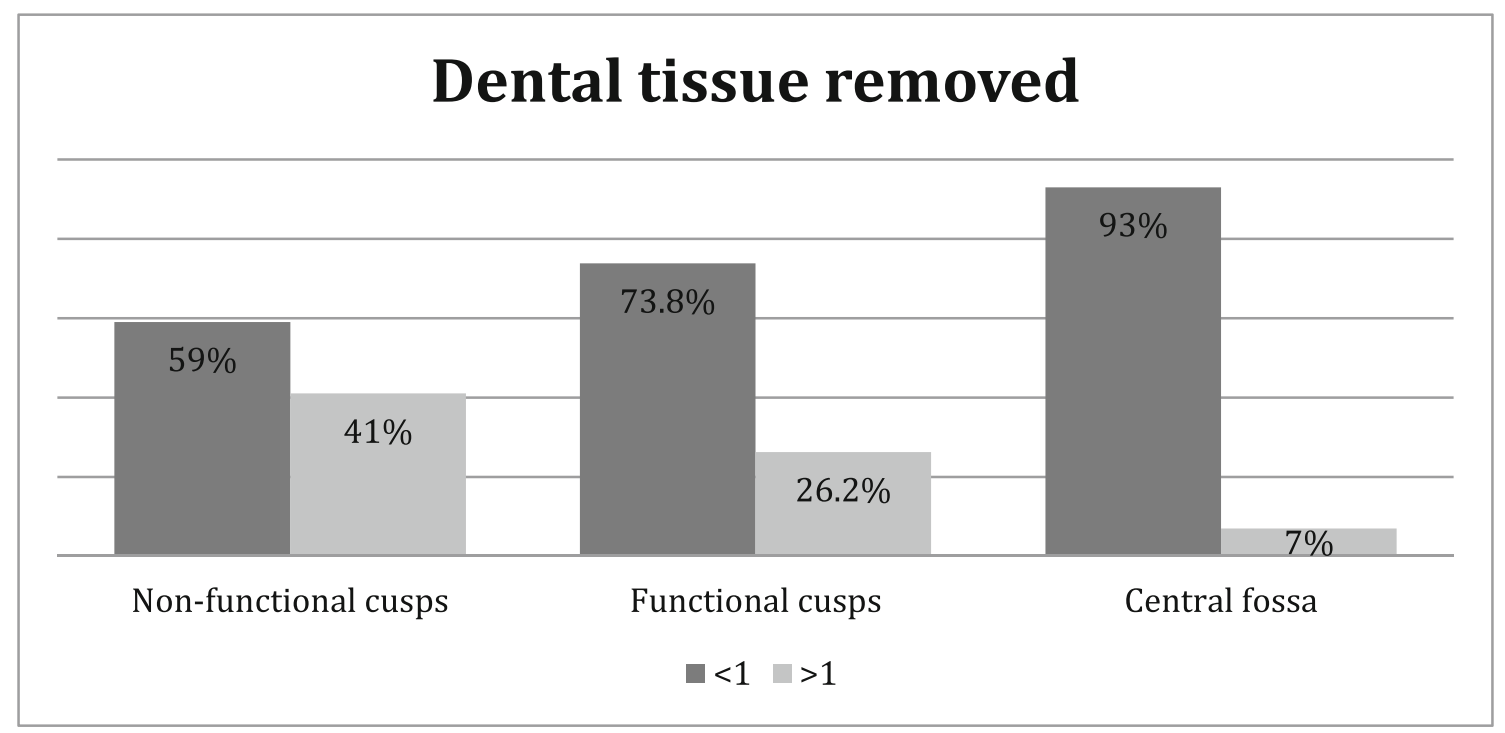

Graph 4 Amount (percentage) of dental tissue removed during preparation (mm) 
that the reduction in thickness does not affect the material bending strength and warrants its use in preparations with minimal dental tissue removal (Table 1). The minimum thicknesses assessed in our study were below the $1.5 \mathrm{~mm}$ recommended by the traditional literature for ceramic restorations. In our study, we had removed $1.1 \mathrm{~mm}$ in the cusps and $0.7 \mathrm{~mm}$ at the fossa, yet no restoration fractures were observed. As to overlay thicknesses, $26 \%$ at the fossa were between 0.5 and $0.9 \mathrm{~mm}$ and $60 \%$ between 1 and $1.5 \mathrm{~mm}$. In the cusps, the thicknesses were higher: only $13 \%$ and $20 \%$ for nonfunctional and functional cusps, respectively, were less than $1.5 \mathrm{~mm}$. Preservation of residual tissues in long-term element survival - especially where caries or erosion have weakened the dental structure - is fundamental $[8,13]$ and entails fewer traumas and better prognosis [8]. A crucial and critical point about this concerns the occurrence of higher loading failure rate, as the supporting tooth structure is predominately made up by enamel, which has a higher elastic module compared with those of dentin $[14,15]$. Disilicate adhesive cementation plays a key role in this context: enamel and lithium disilicate have a very similar elastic module $(80 \mathrm{GPa}$ - which rises to $91 \mathrm{GPa}$ on the occlusal surface - and $95 \mathrm{GPa}$ ), and this allows to develop less tension stresses during chewing load, reducing the threat of ceramic fracture [16]. The fracture risk in thin restorations cemented on enamel is therefore comparable with thicker restorations cemented on dentin; moreover, enamelcemented restorations show less mechanical complications over the years [17].

In an ideal tooth preparation, the aspect that needs most careful evaluation is the amount of dental structure removal required by the material being used. In addition to this, other important clinical criteria that need to be taken into account are residual tooth condition, esthetic and functional aspects, tooth orientation, and occlusion rehabilitation planning.

In most of the preparations analyzed in our study, the amount of dental tissue removed is less than or equal to $1 \mathrm{~mm}$, according to minimum invasive criteria.

However, overlay thicknesses analyzed in our study did not match only the amount of dental tissue removed, but they also depended on required occlusal increase, which we had calculated during the treatment planning phase in order to reestablish a correct occlusal relationship, or an occlusal vertical dimension (OVD) decreased due to dental abrasion [18]. To gain further insight on the matter, in fact we further analyzed our restorations and determined different thickness ratios. On the nonfunctional cusps, the percentage of tooth removal needed was $48 \%$ for ceramic thickness and $52 \%$ for occlusal increase; on the functional cusps and the central fossa, the values of dental tissue removed and occlusal increase were, respectively, $47 \%$ and $53 \%$ in both cases. This explains how the need for obtaining an occlusal increase allows the clinician to carry out more conservative preparations, maintaining the structure of the dental elements and performing adhesion in the enamel.

\section{Conclusions}

Lithium disilicate IPS e.max Press confirmed to be a reliable material for monolithic restorations yielding a highly satisfying survival at 32 months. Its biomechanical characteristics allowed us to work on minimal thicknesses values of $0.7 \mathrm{~mm}$ without affecting the strength.

Future studies extending the follow-up period could be useful to assess the mechanical behavior in these conservative restorations over time and evidence any changes in esthetic performances.

\section{Compliance with ethical standards}

Conflict of interest The authors declare that they have no conflict of interest.

Ethical approval All procedures performed in studies involving human participants were in accordance with the ethical standards of the institutional and/or national research committee and with the 1964 Helsinki declaration and its later amendments or comparable ethical standards.

Informed consent Informed consent was obtained from all individual participants included in the study.

Open Access This article is distributed under the terms of the Creative Commons Attribution 4.0 International License (http:// creativecommons.org/licenses/by/4.0/), which permits unrestricted use, distribution, and reproduction in any medium, provided you give appropriate credit to the original author(s) and the source, provide a link to the Creative Commons license, and indicate if changes were made.

\section{References}

1. Fradeani M, Aquilano A, Bassein L (1997) Longitudinal study of pressed glass-ceramic inlays for four and a half years. J Prosthet Dent 78:346-353

2. Xie KX, Wang XY, Gao XJ, Yuan CY, Li JX, Chu CH (2012) Fracture resistance of root filled premolar teeth restored with direct composite resin with or without cusp coverage. Int Endod J 45: 524-529. https://doi.org/10.1111/j.1365-2591.2011.02005.x

3. Goodacre CJ, Bernal G, Rungcharassaeng K, Kan JYK (2003) Clinical complications in fixed prosthodontics. J Prosthet Dent 90:31-41. https://doi.org/10.1016/S0022391303002142

4. Guess PC, Zavanelli RA, Silva NRFA et al Monolithic CAD/CAM lithium disilicate versus veneered Y-TZP crowns: comparison of failure modes and reliability after fatigue. Int J Prosthodont 23: 434-442

5. Ma L, Guess PC, Zhang Y (2013) Load-bearing properties of minimal-invasive monolithic lithium disilicate and zirconia occlusal onlays: finite element and theoretical analyses. Dent Mater 29: 742-751. https://doi.org/10.1016/j.dental.2013.04.004

6. Simeone P, Gracis S (2017) Eleven-year retrospective survival study of 275 veneered lithium disilicate single crowns. Int $\mathbf{J}$ Periodontics Restorative Dent 35:685-694

7. Gehrt M, Wolfart S, Rafai N, Reich S, Edelhoff D (2013) Clinical results of lithium-disilicate crowns after up to 9 years of service. Clin Oral Investig 17:275-284. https://doi.org/10.1007/s00784012-0700-x 
8. Thompson MC, Thompson KM, Swain M (2010) The all-ceramic, inlay supported fixed partial denture. Part 1. Ceramic inlay preparation design: a literature review. Aust Dent J 55:120-127; quiz 231. https://doi.org/10.1111/j.1834-7819.2010.01214.x

9. Sulaiman TA, Delgado AJ, Donovan TE (2015) Survival rate of lithium disilicate restorations at 4 years: a retrospective study. J Prosthet Dent 114:364-366. https://doi.org/10.1016/j.prosdent. 2015.04.011

10. Mobilio N, Fasiol A, Catapano S (2018) Survival rates of lithium disilicate single restorations: a retrospective study. Int J Prosthodont 31:283-286

11. Edelhoff D, Sorensen JA (2002) Tooth structure removal associated with various preparation designs for posterior teeth. Int $\mathrm{J}$ Periodontics Restorative Dent 22:241-249

12. Zhang Y, Kim J-W, Bhowmick S, Thompson VP, Rekow ED (2009) Competition of fracture mechanisms in monolithic dental ceramics: flat model systems. J Biomed Mater Res B Appl Biomater 88:402-411. https://doi.org/10.1002/jbm.b.31100

13. Piemjai M, Arksornnukit M (2007) Compressive fracture resistance of porcelain laminates bonded to enamel or dentin with four adhesive systems. J Prosthodont 16:457-464. https://doi.org/10.1111/j. 1532-849X.2007.00227.x

14. Habelitz S, Marshall SJ, Marshall GW, Balooch M (2001) Mechanical properties of human dental enamel on the nanometre scale. Arch Oral Biol 46:173-183
15. RG CRAIG, FA PEYTON (1958) Elastic and mechanical properties of human dentin. J Dent Res 37:710-718. https://doi.org/10. $1177 / 00220345580370041801$

16. Guess PC, Selz CF, Steinhart Y-N et al (2013) Prospective clinical split-mouth study of pressed and CAD/CAM allceramic partial-coverage restorations: 7-year results. Int J Prosthodont 26:21-25

17. Clausen J-O, Abou Tara M, Kern M (2010) Dynamic fatigue and fracture resistance of non-retentive all-ceramic fullcoverage molar restorations. Influence of ceramic material and preparation design. Dent Mater 26:533-538. https://doi. org/10.1016/j.dental.2010.01.011

18. Fabbri G, Zarone F, Dellificorelli G et al (2014) Clinical evaluation of 860 anterior and posterior lithium disilicate restorations: retrospective study with a mean follow-up of 3 years and a maximum observational period of 6 years. Int J Periodontics Restorative Dent 34:165-177

Publisher's note Springer Nature remains neutral with regard to jurisdictional claims in published maps and institutional affiliations. 